\title{
The role of income differences in explaining social inequalities in self rated health in Sweden and Britain
}

\author{
M Åberg Yngwe, F Diderichsen, $M$ Whitehead, P Holland, B Burström
}

\begin{abstract}
Study objective-To analyse to what extent differences in income, using two distinct measures-as distribution across quintiles and poverty-explain social inequalities in self rated health, for men and women, in Sweden and Britain.

Design-Series of cross sectional surveys, the Swedish Survey of Living Conditions (ULF) and the British General Household Survey (GHS), during the period 1992-95. Participants and setting-Swedish and British men and women aged 25-64 years. Approximately 4000 Swedes and 12500 Britons are interviewed each year in the cross sectional studies used. The sample contains 15766 people in the Swedish dataset and 49604 people in the British dataset.

Main results-The magnitude of social inequalities in less than good self rated health was similar in Sweden and in Britain, but adjusting for income differences explained a greater part of these in Britain than in Sweden. In Britain the distribution across income quintiles explained $47 \%$ of the social inequalities in self rated health among women and $31 \%$ among men, while in Sweden it explained, for women $13 \%$ and for men $20 \%$. Poverty explained $22 \%$ for British women and $8 \%$ for British men of the social inequalities in self rated health, while in Sweden poverty explained much less (men $2.5 \%$ and women $0 \%$ ).

Conclusions-The magnitude of social inequalities in self rated health was similar in Sweden and in Britain. However, the distribution of income across occupational social classes explains a larger part of these inequalities in Britain than in Sweden. One reason for this may be the differential exposure to low income and poverty in the two countries.

(F Epidemiol Community Health 2001;55:556-561)
\end{abstract}

Department of Public Health, University of Liverpool, UK

$M$ Whitehead

P Holland

Correspondence to: Mrs Åberg Yngwe,

Department of Public Health Sciences, Division of Social

Medicine, Karolinska

Institutet, SE-171 76

Stockholm, Sweden

(monica.aberg-yngwe@)

socmed.sll.se)

Accepted for publication 12 March 2001 interchangeable. ${ }^{3}$ Education determines socioeconomic position in terms of occupational class and socioeconomic position determines income.

The magnitude of differences in health between social positions are surprisingly similar in different European countries, including the Scandinavian welfare states, ${ }^{24}$ while the mechanisms generating these differences may be different. ${ }^{5}$ During the past decade there has been a growing interest in the association between income/poverty and mortality/ morbidity, ${ }^{6-11}$ and the roles of income and poverty in contributing to socioeconomic inequalities in health. There has also been a growing interest in conducting comparative studies on social determinants of health. ${ }^{611}{ }^{12}$ The differences between welfare systems in western European countries allow us to compare the impact of income and poverty on socioeconomic inequalities in Sweden and Britain. In this study we have chosen to define socioeconomic position by occupational social class. The concept of social class, or socioeconomic position/group, is grounded in the function of society. In sociological theory about inequality a distinction is made between positions in social structure and the persons occupying these. ${ }^{13}$ Using the concept occupational social class is a way to try to see what constitutes these different positions and the life chances for the people who occupy them. The concept occupational social class has been used in a previous study. ${ }^{11}$

The aim of the study is to analyse the role of differences in income, using two distinct measures - as distribution across quintiles and poverty - in explaining social inequalities in self rated health among men and women in Sweden and Britain. In relation to previous studies, our interest is to study income as a mediating factor in the association between occupational social class and health - not to use income as a measure of socioeconomic position. We would argue that our comparative perspective may also contribute to the ongoing discussion on the relation between income distribution and health. Comparing the role of income in explaining socioeconomic inequalities in Sweden and Britain provides us with two different contexts, with different income distributions, within which the relation between income and health on an individual level is analysed.

\section{Methods}

SOURCES OF DATA

The study is based on a series of cross sectional surveys containing measures of health and living conditions, the Swedish Survey of Living 
Conditions (ULF) and the British General Household Survey (GHS). The years 1992-95 were pooled to yield the analysed datasets. Both datasets include men and women, and approximately 4000 Swedes and 12500 Britons are interviewed each year. In the Swedish ULF the non-response rates have gradually increased to $20 \%$ in 1995 and in the British GHS the non-response rate has been about $18 \%$ over the whole time period. Our sample contained 15766 people in the Swedish dataset and 49604 people in the British, aged 25-64 years. While the British survey samples are household based the Swedish samples are based on individuals. This results in higher odds for smaller British households to be included in the study, although, the comparability between the countries would not be affected as we have controlled for marital status and used household income adjusted for household size.

MEASURE OF OCCUPATIONAL SOCIAL CLASS

In the Swedish data the Swedish Socioeconomic Classification (SEI) was used to measure occupational social class. The British GHS used the registrar general's socioeconomic classification. To enable comparison between the countries the occupations were aggregated into the same four groups - higher non-manual employees, lower non-manual employees, qualified manual workers and unqualified manual workers as done in a previous study. ${ }^{14}$ People who could not be classified in this manner were excluded from the analysis. Groups whose social position is primarily a consequence of their health status-people who are retired early because of permanent sicknesswere excluded from the analysis to reduce the complication of reversed causation. In the Swedish sample self employed workers were also excluded as their income is often misclassified because of taxation rules, they often report a low income even though they may not lack economical resources. In the British data there is no reason to exclude the self employed, as these are not misclassified. They are also, in our data, sorted into the different social classes and not possible to exclude from the analysis. From the British dataset 1603 (6.3\%) women and $2058(8.2 \%)$ men were excluded because of the stated reasons. For the same reasons we excluded $848(10.9 \%)$ women and $688(8.8 \%)$ men from the Swedish dataset. Also 1349 $(8.7 \%)$ Swedish men and women were excluded because they were self employed.

MEASURE OF INCOME AND POVERTY

For the Swedish sample data on income status were obtained by Statistics Sweden from the national tax register and linked to each person by their personal identification number, resulting in a small proportion $(1.5 \%)$ of persons with missing values on the income variable. In the British GHS each respondent declared their income during the interview, which resulted in a higher proportion $(12.5 \%)$ of missing values. The measure of income is the disposable household income, deflated and adjusted to household size in an identical way using the Statistics Sweden Equivalence Scale in both countries. ${ }^{15}$ In the equivalence scale one adult counts as 1.16 , two adults as 1.92 , children between $0-3$ years as 0.56 each, children $4-10$ years as 0.66 each, children 11-17 as 0.76 each.

In both countries the income distribution is expressed across quintiles and poverty measured in accordance with the EU definition as having an income below $50 \%$ of the median income. Low income was defined as having an income in the lowest two quintiles of the income distribution. The income distribution and therefore also the income quintiles and the poverty measure is based on the income in the population aged $16-84$ years.

MEASURE OF SELF RATED HEALTH

Lundberg and Manderbacka ${ }^{16}$ showed that the measure of self rated health has a high reliability and is useful when measuring the health status in populations. Poor self rated health is associated with a higher mortality risk. ${ }^{17}$ In the Swedish and British surveys the wording of the question on self rated health differs to some extent.

Sweden: How do you consider your general health? Is it good, bad or something in between?

Britain: Over the last 12 months would you say your health has on the whole been good, fairly good or not good?

While both questions share the same responses they differ in the sense that the British question measures health over the year up to interview. The self rated health variable was dichotomised and aggregated into "good" and "less than good" health.

\section{DATA ANALYSIS}

Logistic regression analysis was used to adjust for confounders and mediating factors. The explained fraction (XF) estimates the proportion of excess risk explained by mediating factors, which in this study are the distribution across income quintiles and poverty. ${ }^{18}$ The explained fraction is calculated from the odds ratios among manual workers with non-manual employees as reference group, before adjustment (OR) and after adjustment for potential mediating factors $\left(\mathrm{OR}^{\star}\right)$;

$$
(\mathrm{XF})=\frac{\left((\mathrm{OR}-1)-\left(\mathrm{OR}^{*}-1\right)\right)}{(\mathrm{OR}-1)}
$$

\section{Results}

THE DISTRIBUTION OF LOW INCOME AND

POVERTY BY OCCUPATIONAL SOCIAL CLASS

The social gradient in the prevalence of low income was steeper in Britain than in Sweden for both men and women, with a higher prevalence of low income among British manual workers compared with their Swedish peers (table 1). Female manual workers in Sweden and all British women, particularly lower nonmanual and manual groups, had a higher prevalence of low income than their male peers. Table 2 shows that the prevalence of poverty was also lower in Sweden than in Britain. There were also smaller social differences 
Table 1 Prevalence (\%) of low income among men and women by occupational social class in Sweden and Britain, 1992-95

\begin{tabular}{llllll}
\hline & \multicolumn{2}{l}{$\begin{array}{l}\text { Prevalence of low income (two lowest } \\
\text { quintiles) }\end{array}$} \\
\cline { 2 - 3 } $\begin{array}{l}\text { Occupational social } \\
\text { class }\end{array}$ & Sweden & & \multicolumn{2}{l}{ Britain } \\
\cline { 2 - 3 } \cline { 5 - 6 } & Men & Women & & Men & Women \\
\hline Higher non-manual & 17.1 & 17.9 & & 18.9 & 19.2 \\
Lower non-manual & 22.5 & 22.2 & & 23.0 & 30.4 \\
$\begin{array}{l}\text { Qualified manual } \\
\text { Unqualified manual }\end{array}$ & 28.2 & 37.1 & & 39.0 & 45.9 \\
Number in sample & 6111 & 6525 & & 19.5 & 57.4 \\
\hline
\end{tabular}

Table 2 Prevalence (\%) of poverty among men and women by occupational social class in Sweden and Britain, 1992-95

\begin{tabular}{llllll}
\hline & \multicolumn{3}{c}{$\begin{array}{l}\text { Prevalence of poverty } \\
\text { inc) }\end{array}$} & \multicolumn{2}{l}{ (<0\% of median } \\
\cline { 2 - 3 } $\begin{array}{l}\text { Occupational social } \\
\text { class }\end{array}$ & Sweden & & & Britain \\
\cline { 2 - 3 } \cline { 5 - 6 } & Men & Women & & Men & Women \\
\hline Higher non-manual & 2.3 & 1.8 & & 8.5 & 8.2 \\
Lower non-manual & 2.3 & 2.8 & & 10.5 & 13.8 \\
Qualified manual & 3.2 & 2.4 & & 18.8 & 21.2 \\
Unqualified manual & 3.6 & 4.1 & & 26.2 & 28.7 \\
Number in sample & 6111 & 6525 & & 19344 & 21145 \\
\hline
\end{tabular}

in the distribution of poverty in Sweden than in Britain. Within each occupational social class the prevalence of both low income and poverty was higher among British men and women than their Swedish peers. In both countries the prevalence of low income and poverty was highest among unqualified manual women.

RISK OF LESS THAN GOOD SELF RATED HEALTH BY OCCUPATIONAL SOCIAL CLASS

The absolute levels of less than good health (data not shown) were lower overall in Sweden than in Britain. We do not know if this is an effect of the differences in the self rated health question between the two countries or if it is because of some other difference in context between the two countries. Although cross country comparisons may be biased in this

Table 3 Odds ratios (95\% CI) for less than good health for men and women, in Sweden and Britain, 1992-95. Adjusted for age, marital status and foreign born

\begin{tabular}{|c|c|c|c|c|}
\hline \multirow[b]{2}{*}{ Occupational social class } & \multicolumn{2}{|l|}{ Sweden } & \multicolumn{2}{|l|}{ Britain } \\
\hline & Men & Women & Men & Women \\
\hline $\begin{array}{l}\text { Higher non-manual } \\
\text { (reference group) }\end{array}$ & 1.00 & 1.00 & 1.00 & 1.00 \\
\hline Lower non-manual & $1.50(1.2,1.9)$ & $1.23(1.0,1.5)$ & $1.20(1.1,1.3)$ & $1.18(1.1,1.3)$ \\
\hline Qualified Manual & $1.86(1.6,2.2)$ & $1.59(1.3,1.9)$ & $1.60(1.5,1.7)$ & $1.43(1.3,1.6)$ \\
\hline Unqualified Manual & $2.16(1.8,2.6)$ & $2.17(1.9,2.5)$ & $2.04(1.8,2.2)$ & $1.81(1.6,2.0)$ \\
\hline
\end{tabular}

Table 4 Odds ratios (95\% CI) for less than good health for men and women within income quintiles and for people defined as poor (income below 50\% of median income) in Sweden and Britain. Adjusted for age, marital status and foreign born

\begin{tabular}{llllll}
\hline & \multicolumn{2}{l}{ Sweden } & & \multicolumn{2}{l}{ Britain } \\
\cline { 2 - 3 } \cline { 5 - 6 } Quintile group & Men & Women & & Men & Women \\
\hline Highest income & 1.00 & 1.00 & & 1.00 & 1.00 \\
Inc 80 & $1.49(1.2,1.8)$ & $1.44(1.2,1.7)$ & & $1.35(1.2,1.5)$ & $1.37(1.2,1.5)$ \\
Inc 60 & $1.71(1.3,2.1)$ & $1.50(1.2,1.8)$ & & $1.62(1.5,1.8)$ & $1.65(1.5,1.8)$ \\
Inc 40 & $1.71(1.4,2.2)$ & $1.70(1.4,2.1)$ & & $1.88(1.7,2.1)$ & $1.85(1.7,2.0)$ \\
Lowest income & $2.38(1.8,3.1)$ & $1.67(1.3,2.1)$ & & $2.18(1.9,2.4)$ & $2.48(2.2,2.7)$ \\
Not poor & 1.00 & 1.00 & & 1.00 & 1.00 \\
Poor & $1.89^{\star}(1.2,3.0)$ & $1.16(0.8,1.7)$ & & $1.56(1.4,1.7)$ & $1.68(1.6,1.8)$ \\
\hline
\end{tabular}

${ }^{\star}$ An interaction term is included in this logistic regression model because of a strong negative interaction between poverty and foreign born. way, it may be valid to compare the differences in absolute prevalence rates between occupational social classes. The rate differences between higher non-manual employees and unqualified manual workers were similar among British and Swedish men and women.

The social inequalities in less than good self rated health, measured as odds ratios, were substantial and approximately of the same size in both countries (table 3 ). The social gradient was somewhat less pronounced among British women than among British men and among Swedish men and women.

RISK OF LESS THAN GOOD HEALTH BY INCOME QUINTILE AND BY POVERTY

The odds ratios for less than good health for men and women were calculated by income quintiles and for those defined as poor (table 4). In the model for poverty, among Swedish men a strong negative interaction between poverty and being foreign born was found. Therefore an interaction term was included. For the income quintile model no such interaction was found. Odds ratios for less than good health did not differ to a great extent within income quintiles between the two countries, except between women within the lowest income quintile in Sweden (1.67 95\% CI 1.3, 2.1 ) and Britain (2.48 95\%CI 2.2, 2.7). The income gradient in odds ratios for less than good health differed slightly from the gradient between occupational social classes, particularly among women (table 3 and 4). While the occupational social gradient was more pronounced among Swedish women, the income gradient was steeper among British women. In Britain poor men and women had a significantly greater odds ratio of less than good health $1.56(95 \% \mathrm{CI} 1.4,1.7)$ and $1.68(95 \% \mathrm{CI}$ $1.6,1.8)$ compared with people who are not poor. In Sweden the odds ratios between the poor and not poor were for men 1.89 (95\% CI $1.2,3.0)$ and for women $1.16(95 \%$ CI 0.8 , 1.7), when including the interaction term in the model for men.

\section{EXPLAINED FRACTION OF LOW INCOME AND} POVERTY

The explained fraction (XF) was calculated to analyse the role of poverty and income distribution across quintiles in explaining social inequalities in self rated health among men and women in Sweden and Britain. The distribution of income, as divided into quintiles with the highest $20 \%$ as reference group, explained $19.8 \%$ of the inequalities in health between Swedish men in different occupational social classes and $13.2 \%$ of the differential between Swedish women, while it explained $31.1 \%$ and $47.0 \%$ for British men and women respectively (table 5). The explained fraction for poverty in Sweden was small $2.5 \%$ for men and zero for women) compared with in Britain where poverty explained $8.2 \%$ for men and $21.6 \%$ for women. Among Swedish men, an interaction term between poverty and foreign born was included when calculating the explained fraction for poverty. 
Table 5 Explained fraction (XF) of the income and poverty differential in odds of less than good health for manual and non-manual men and women in Sweden and Britain, 1992-95 Model A: controls for age, marital status and foreign born Model B: Model A plus income quintile groups Model C: Model A plus poverty (below 50\% of median income)

\begin{tabular}{llllll}
\hline \multicolumn{3}{c}{ Odds ratios } & & & \\
\cline { 2 - 3 } & Model $A$ & Model $B$ & Model $C$ & XFincome & \multirow{2}{*}{ XFpoverty } \\
\hline Sweden & & & & & \\
Non-manuals ref group & 1.00 & 1.00 & 1.00 & & \\
Men $\dagger$ & 1.81 & 1.65 & $1.79 \ddagger$ & $19.8 \%$ & $2.5 \%$ \\
Women $\dagger$ & 1.83 & 1.72 & 1.83 & $13.2 \%$ & $0 \%$ \\
Britain & 1.00 & 1.00 & 1.00 & & \\
Non-manuals ref group & & & & \\
Men $\dagger$ & 1.61 & 1.42 & 1.56 & $31.1 \%$ & $8.2 \%$ \\
Women $\dagger$ & 1.51 & 1.27 & 1.40 & $47.0 \%$ & $21.6 \%$ \\
\hline
\end{tabular}

*The reference group, non-manuals, includes higher non-manuals and lower non-manuals. †The manual group includes qualified manual workers and unqualified manual workers. $\ddagger$ An interaction term is included in this logistic regression model because of a strong negative interaction between poverty and foreign born. reasons behind this. A large proportion of British female unqualified manual workers have an income within the lowest income quintile, which contributes to the larger explained fraction of income and poverty for British women.

Men and women aged 25-64 years in both Britain and Sweden were included in the analyses to enable comparison of these two contexts. All other causes of non-employment than age beyond this interval, including occupational pension before age 65, are regarded as part of the mechanism. British women are therefore included up to age 64, even though age 60 is their retiring age. Restricting the analysis of British women to the age group 25-59 years did not however change the result significantly. The explained fractions for British women were $49 \%$ for low income and $25 \%$ for poverty when using age $25-59$, instead of $47 \%$ for low income and $22 \%$ for poverty when using age 25-64. British women over age 59 years did not to a larger extent lack occupational social classification, the proportion of women not classifiable by occupational social class was similar for all age groups. also in the distribution of poverty among men and women in Britain. Among Swedish female unqualified manual workers $14.3 \%$ had an income within the lowest quintile compared with $27.5 \%$ of their British peers, while $12.4 \%$ of Swedish male unqualified manual workers and $24.8 \%$ of their British peers had an income within the lowest quintile (data not shown). The overall prevalence rates of less than good health were higher in Britain than in Sweden, but this might have been influenced by the differences between the Swedish and the British question on self rated health. There was a social gradient in the odds of having less than good health in both countries, of the same magnitude in Sweden and in Britain. However, the social gradient was less pronounced among British than among the Swedish female unqualified manual workers. The explained fraction of income quintiles and poverty on health was, on the other hand, larger in Britain than in Sweden. Hence, even though social inequalities seem to be similar in size, the mechanisms leading to these inequalities might differ. These differences in pathways to inequalities in health were also found in a previous comparative study between Britain and Sweden concerning the health status of lone mothers. ${ }^{5}$

A crude income measure, such as income before taxation, would indicate the individuals' wage level in society. Using equivalised disposable household income, however, as in this study, indicates the person's ability to consume. In their comparative study Rahkonen et al used both gross individual income and net household equivalent income as two different income indicators. Their results show household equivalent income to be more strongly associated with health. ${ }^{11}$

The main result in this study is that the income distribution across quintiles and poverty seemed to explain more of the occupational social class differences in self rated health in Britain than in Sweden, for both men and women. The differential exposure to low income in the two countries is one of the

\section{LIMITATIONS OF THE STUDY}

To minimise the risk of reversed causation, that is, ill health leading to poverty or low income rather than vice versa, the groups whose social position is primarily a consequence of their health status were excluded from the analysisset and the "early retired/permanently sick" in the British dataset. Because of differences in insurance systems, permanently sick and early Excluding these groups might result in a larger underestimation of the role of differences in income for the social inequalities in Britain than in Sweden. We also excluded people nonclassifiable by occupational social class in both countries. As there are fewer women on the labour market in Britain than in Sweden, there might be an underestimation of the social inequalities in health in Britain attributable to a healthy worker effect. This could to some extent explain the difference between British and Swedish women in table 3 and has previously been discussed by Arber and Lahelma. ${ }^{19}$ The exclusion of the self employed from the Swedish dataset may also to some extent have affected the results and the generalisability.

Misclassification may have occurred in the measurement of income in Britain, as it is self reported, and in Sweden, because of allowable deductions and differences in taxation rules. There was also a difference in the proportion of missing values on the income variable in the two datasets. In Britain $12.5 \%$ had missing values compared with $1.5 \%$ in Sweden. However, it is unlikely that the proportion of missing values on the income variable is differential across occupational social classes and therefore would have seriously biased our results. The measure of household income takes into account all income, both wages and benefits, net of taxes and adjusted for price inflation, family size and composition. A that is, the "early retired" in the Swedish dataretired are poorer in Britain than in Sweden. 
relative poverty measure and income distribution across quintiles were used in this study. These quintiles may not fully reflect the differences in income distribution in Sweden and Britain.

The wording of the self rated health question in the ULF and GHS differs to some extent and the consequences this might have on the overall rates of fair or poor self rated health are difficult to predict. As the absolute levels of less than good self rated health are quite different within the two countries, the question itself might affect the overall levels. This study, however, is comparing the relative, not the absolute, levels, and the gradients in less than good self rated health within each country, and therefore should not be subject to this type of bias.

COMPARISONS WITH OTHER STUDIES-

INTERPRETATION OF RESULTS

Social inequalities in health were substantial and similar in size in both countries (table 3). This supports earlier findings that the Scandinavian countries do not necessarily have smaller socioeconomic inequalities in health despite the more redistributive welfare system. ${ }^{2}$ Even if relative differences in these countries may be larger, in a letter to the editor, Vågerö and Eriksson showed the absolute differences to be lower in Sweden, but not in the Scandinavian countries in general. ${ }^{20}$ Cavelaars et $a l^{4}$ show that when using income level as an indicator of socioeconomic status health inequalities were smaller in more egalitarian countries, such as Sweden, than when using educational level. ${ }^{6}$ They propose that while egalitarian socioeconomic policies in the Nordic countries may have reduced the effect of income on health they were not as successful in reducing health inequalities related to educational level. Smaller income related inequalities in health in Sweden have also been confirmed by van Doorslaer et $a l^{21}$ who studied income related inequalities in self rated health in nine industrialised countries.

Rahkonen $e a^{11}$ also used the British GHS in their comparative study on income inequalities and health in Britain and Finland. One purpose of their study was to analyse whether the income and health relation could be explained by employment status, education and occupational class in the two countries. The purpose of the present study was to study whether occupational social class differences in health could be explained by differences in income. We used two expressions of economic situation-income distributed across quintiles and poverty, defined as an income below 50\% of the median income in the country. Absolute measures of economic resources might have been useful to include in this study as a complement to the relative measures, such as minimum subsistence level, cash margin, car ownership and housing tenure. The meaning and importance of absolute measures, however, may differ between the two countries, therefore the comparisons of these have not been attempted in this study. An earlier study by Lundberg ${ }^{22}$ showed that small financial
KEY POINTS

- Income was more unevenly distributed between occupational social classes in Britain than in Sweden.

- Social inequalities in self rated health were similar in Sweden and in Britain.

- The distribution of income explained a larger part of the social inequalities in self rated health in Britain than in Sweden.

- The difference between the two countries in the role of income is particularly pronounced among women.

resources were not a causative factor to class differences in ill health in Sweden. Even so, it would have been interesting to measure it in this comparative study, as our results indicate that income explains less of the social inequalities in health in Sweden than in Britain. In his comparative study between Britain and Sweden Halleröd found that Britons were more deprived according to British standards than Swedes according to Swedish standards. ${ }^{23}$

We found that the odds ratios of less than good health in different occupational social classes showed smaller inequalities among British women (unqualified manual workers 1.81) compared with Swedish women (unqualified manual workers 2.17), while the odds of less than good health in different income quintiles showed larger inequalities among British women (lowest quintile 2.48) compared with Swedish women (lowest quintile 1.67). This result adds to the importance of a discussion on the choice of measure of socioeconomic position and what dimension of the socioeconomic position the different measures really capture. In both of these regression analyses we have controlled for age, marital status and being foreign born. The smaller social inequalities among British women may, to some extent, be an effect of the different ways of classifying women. Swedish women are more established in the labour market than British women and the vast majority are classified according to their own current or last labour market position. In Britain downward occupational mobility among women on returning to work after child rearing may lead to a diluted effect of social inequalities in Britain. ${ }^{19}$

Despite the finding that the size of the social inequalities are approximately the same size in both countries, the mechanisms generating these inequalities seem to differ. The results show that the income distribution across quintiles and poverty seem to explain a larger part of the social inequalities in Britain than in Sweden, which may be attributable to the differential exposure of low income and poverty in the two countries. We believe that further comparable individual level studies, in contrasting social policy contexts, might generate policy relevant knowledge on how to tackle social inequalities in health.

Useful comments on previous drafts of this paper from Olle Lundberg and Johan Fritzell, Swedish Institute for Social Research in Stockholm are gratefully acknowledged. 
Data from the British General Household Survey were made available through the Office for National Statistics and the ESRC Data Archive. The ESRC, the original collectors of the
data, and the Data Archive bear no responsibility for the analyses or interpretations presented here.

Funding: M Åberg Yngwe and B Burström are funded by grants from the Stockholm County Council. F Diderichsen is funded by grants from the National Institute of Public Health. M Whitehead was funded by the Rockefeller Foundation, New York.

Conflicts of interest: none.

1 Fox J, ed. Health inequalities in European Countries. Aldershot: Gower Publishing Company, 1989

2 Mackenbach JP, Kunst AE, Cavelaars AEJM, et al. Socioeconomic inequalities in morbidity and mortality in western Europe. Lancet 1997;349:1655-9.

3 Berkman LF, Macintyre S. The measurement of social class in health studies: old measures and new formulations. IARC Sci Publ 1997; 138:51-64.

4 Cavelaars A, Kunst A, Geurts J, et al. Differences in self-reported morbidity by educational level: a comparison of 11 Western European countries. F Epidemiol Community Health 1998:52;219-27.

5 Whitehead M, Burström B, Diderichsen F. Social policies and the pathways to inequalities in health: a comparative analysis of lone mothers in Britain and Sweden. Soc Sci Med 2000;50:255-70.

6 Cavelaars AEJM, Kunst AE, Geurts JJM, et al. Differences in self-reported morbidity by income level in six European self-reported morbidity by income level in six European
countries. [PhD thesis.] Rotterdam: Department of Public countries. [PhD thesis.] Rotterdam: Department

7 Stronks K, van de Mheen HD, Mackenbach JP. A higher prevalence of health problems in low income groups. $\mathcal{F}$ Epidemiol Community Health 1998;52:548-57.

8 Wilkinson R. Socioeconomic determinants of health: Health inequalities: relative or absolute material standards? $B M f$ 1997;314:591-5.

9 Ecob R, Davey Smith G. Income and health: what is the nature of the relationship? Soc Sci Med 1999;48:693-705.

10 Fritzell J, Lundberg O. Income change and health: on the importance of absolute and relative income for health status in Sweden. Stockholm: SOFI, reprint series no 452.
11 Rahkonen O, Arber S, Lahelma E, et al. Understanding income inequalities in health among men and women in income inequalities in health among men and women
Britain and Finland. Int f Health Serv 2000;30:27-47.

12 Lahelma E, Arber S. Health inequalities among men and women in contrasting welfare states: Britain and three Nordic countries compared. Eur 7 Public Health 1994;4: 213-26.

13 Sorensen A. The basic concepts of stratification research: class, status and power. In: Grusky D, ed. Social stratification in sociological perspective. Boulder: Westview stratification

14 Whitehead M. Bridging the gap. Working towards equity in health and health care. [PhD Thesis.] Sundbyberg: Karolinska Institutet, 1997.

15 Statistics Sweden. Living conditions and inequality in Sweden-a 20-year perspective 1975-1995 (in Swedish). Stockholm: Statistics Sweden, 1997.

16 Lundberg $\mathrm{O}$, Manderbacka $\mathrm{K}$. Assessing reliability of a measure of self-rated health. Scand F Soc Med 1996;24: 218-24.

17 Idler EL, Benjamini Y. Self-rated health and mortality. A review of twenty-seven community studies. F Health Soc Behav 1997;38:21-37.

18 Lynch JW, Kaplan GA, Cohen RD, et al. Do cardiovascular risk factors explain the relation between socioeconomic status, risk of all-cause mortality, cardiovascular mortality and acute myocardial infarction? Am f Epidemiol 1996;144: and acute

19 Arber S, Lahelma E. Women, paid employment and ill-health in Britain and Finland. Acta Sociologica 1993;36: 121-38

20 Vågerö D, Eriksson R. Socioeconomic inequalities in morbidity and mortality in western Europe. Lancet 1997;350:516.

21 van Doorslaer E, Wagstaff A, Bleichrood $\mathrm{H}$, et al. Income-related inequalities in health: some international comparisons. F Health Econ 1997;16:93-112.

22 Lundberg O. Den ojämlika hälsan. [PhD Thesis.] Stockholm: Swedish Institute for Social Research, 1990.

23 Halleröd B. Poor Swedes, poor Britons: a comparative analysis of relative deprivation. In: Andre $\beta \mathrm{H}$, ed. Empirical gate, 1998. 